\title{
Occurrence of hybrids and laboratory evidence of fertility among three species of the Phyllosoma complex (Hemiptera: Reduviidae) in Mexico
}

\author{
José Alejandro Martínez-Ibarra¹/+, Paz María Salazar-Schettino², Benjamín Nogueda-Torres ${ }^{3}$, \\ Mauro Omar Vences², José María Tapia-González ${ }^{3}$, Bertha Espinoza-Gutiérrez ${ }^{4}$
}

1Área de Entomología Médica, Centro Universitario del Sur, Universidad de Guadalajara, AP 20, 49000 Ciudad Guzmán, Jalisco, México ²Laboratorio de Biología de Parásitos, Facultad de Medicina ${ }^{3}$ Escuela Nacional de Ciencias Biológicas, Instituto Politécnico Nacional, México DF, México

${ }^{4}$ Departamento de Inmunología, Instituto de Investigaciones Biomédicas, Universidad Nacional Autónoma de México, México DF, México

In seven studied communities of Western Mexico, triatomine specimens were sympatrically collected, some with atypical morphological characteristics in contrast to pure specimens, which were presumed to be hybrids. More than 200 specimens of Meccus pallidipennis and Meccus longipennis with brown-yellow markings on dorsal connexival segments were collected in Ahuacapán and Quitupan. In La Mesa, more than 60 specimens similar to Meccus picturatus in most morphological characteristics (including size) were collected, although they presented a largely yellowish corium like M. pallidipennis. Interfertility was proven between all of the studied wild hybrid specimens, as well as between all the experimental laboratory hybrids. Two different phenotypes (M. picturatus and M. longipennis) were obtained from crosses between M. picturatus $x$ M. picturatus and M. longipennis $x$ M. longipennis from the three studied localities in state of Nayarit as from La Mesita. Results support the hypothesis that the subspecific ranking of those triatomines may, therefore, be more appropriate because reproductive isolation has not been developed and complete interbreeding was recorded.

Key words: Triatominae - hybrids - Meccus - Phyllosoma complex - Mexico

In Mexico, more than 30 species of triatomines have been recorded. Nine of them are considered important vectors of Trypanosoma cruzi to human populations (Cruz-Reyes \& Pickering-López 2006). Amongst these can be included the five more distributed species of the Phyllosoma complex, Meccus phyllosomus (Burmeister), Meccus longipennis (Usinger), Meccus pallidipennis (Stål), Meccus picturatus (Usinger) and Meccus mazzottii (Usinger). The species traditionally considered as members of that complex have been members of a group with systematic problems. More than 60 years ago, most of them (except for the 6th member, undescribed then, Meccus bassolsae) (Alejandre-Aguilar, Nogueda-Torres, Cortez-Jiménez, Jurberg, Galvão, Carcavallo) were ranked as subspecies of $M$. phyllosomus (Mazzotti \& Osorio 1942). Lent and Wygodzinsky (1979) reinstated the other five as bona fide species based entirely on morphological characters. Since then, an argument about their proper taxonomic rank has developed. Even though some researchers have considered some of these species as subspecies (Espinoza-Gómez et al. 2002), most have considered them as species until recently, when molecular evidence led once again to the proposal [as Mazzotti \& Osorio (1942) did] to consider them as subspecies of

Financial support: COECyT-JAL (17-2002), University of Guadalajara (CUSUR-UDG-2009-06), PAPIIT IN (DGAPA, UNAM 212806)

+ Corresponding author: aibarra@cusur.udg.mx

Received 9 July 2009

Accepted 4 November 2009
M. phyllosomus (Bargues et al. 2000, 2008, Marcilla et al. 2001, Martínez et al. 2006, 2010). However, even though that molecular evidence seems to be forceful, biological evidence is still incomplete because conclusions from some of those previously carried out studies have been based on null or a small number of crosses among the species of the Phyllosoma complex (Mazzotti \& Osorio 1942, Mazzotti 1943, Usinger et al. 1966). Even though a recent study (Martínez-Ibarra et al. 2008b) has contributed to give some light in knowing the degree of reproductive isolation between some of the species of the Phyllosoma complex under laboratory conditions, finding natural hybrids could contribute to strengthening the biological evidence.

Even though many researchers (Flores et al. 2001, Espinoza-Gómez et al. 2002, Breniere et al. 2007, Martínez-Ibarra et al. 2008a, 2009, Sandoval-Ruiz et al. 2008, Bosseno et al. 2009) have sampled in many overlapping areas of species of the Phyllosoma complex, the collection of apparent non-pure specimens has been reported in only two studies (Breniere et al. 2007, Martínez-Ibarra et al. 2008a). A feasible reason could be that hybrid offspring of some crosses between species are morphologically indistinguishable from one of the parental lines, such as when specimens of different species were crossed (M. mazzottii х M. bassolsae and M. longipennis x $M$. picturatus) (Martínez-Ibarra et al. 2008b). Besides that, an apparent lack of interest was detected in all of these eight mentioned field studies in growing those specimens from overlapping areas to determine fertility and morphological characteristics of their offspring because in all of them, any data about further studies concerning those parameters, including specimens possibly originating from the natural cross of two of those species, are 
omitted. These parameters could be strong evidence of the subspecies rank of that studied group.

Therefore, within the framework of research on the Phyllosoma complex in Mexico, this study was conducted to analyse the viability and fertility of those specimens found in areas of overlap of some of the species of the Phyllosoma complex in order to obtain additional information that may contribute to establishing the appropriate level for their taxonomical assignment.

\section{MATERIALS AND METHODS}

Study area - As a part of a study about Triatominae species of the Phyllosoma complex in Western Mexico, seven localities in areas where more than one species of the Phyllosoma complex had been reported (Martínez-Ibarra et al. 2001, SSJ 2005) were searched. Four localities were in southern and western state of Jalisco: Ahuacapán $\left(19^{\circ} 40^{\prime} \mathrm{N}, 104^{\circ} 19^{\prime} \mathrm{W}\right)$, in the municipality of

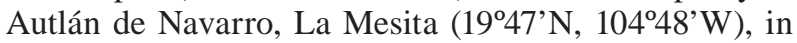
the municipality of Villa Purificación, La Mesa (20²3'N, $104^{\circ} 56^{\prime} \mathrm{W}$ ), in the municipality of Talpa de Allende, and Quitupan (19\%49'N, $\left.104^{\circ} 21^{\prime}\right)$, in the municipality of Quitupan (SEGOB 2005). The remaining three studied localities were in the neighbouring southern and central state of Nayarit: Compostela $\left(21^{\circ} 15^{\prime} \mathrm{N}, 104^{\circ} 53^{\prime} \mathrm{W}\right)$, in the municipality of Compostela, Francisco I. Madero $\left(21^{\circ} 33^{\prime} \mathrm{N}, 104^{\circ} 49^{\prime} \mathrm{W}\right)$, in the municipality of Tepic, and Xalisco $\left(21^{\circ} 27^{\prime} \mathrm{N}, 104^{\circ} 52^{\prime} \mathrm{W}\right)$, in the municipality of Xalisco (Fig. 1) (SEGOB 2005).

Collection of triatomines - From April-September 2007, 12 field trips of three days each were done to investigate the natural ecotopes of bugs (birds' nests, hollow trees and cracks, ground holes, railings, heaps of stones etc.) and the ecotopes in human dwellings using the person per hour technique (Pinchin et al. 1981). Indoor (domestic) sites consisted of the interior of the houses and attached buildings, whereas outdoor (peridomestic) sites were those located within $50 \mathrm{~m}$ of the actual living quarters of the inhabitants (Martínez-Ibarra et al.

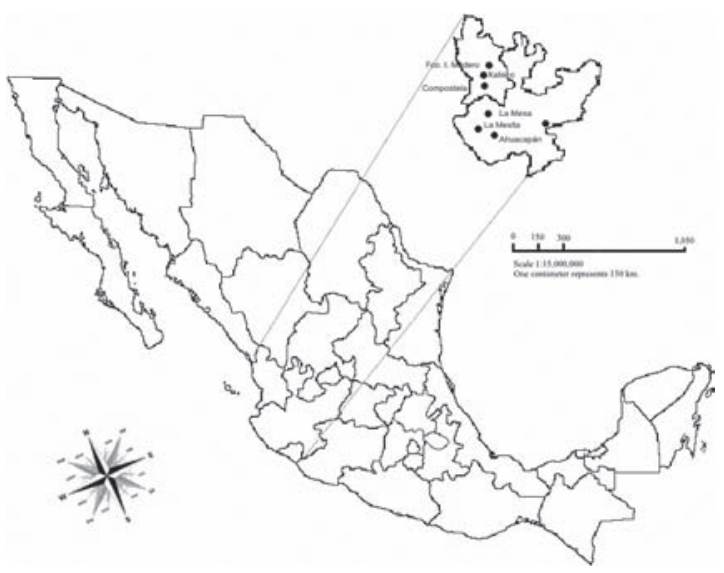

Fig. 1: localities in the collection area of sympatric species of the Phyllosoma complex in Western Mexico.
2001, 2008a) and wild habitats were considered those sites further than $50 \mathrm{~m}$ from the actual living quarters of the inhabitants. Triatominae were collected using tweezers and were placed into plastic containers, which were labelled with the collection data (place of capture and sex). Identification of specimens was performed with the keys of Lent and Wygodzinsky (1979).

Crosses of Triatominae captured in the field - These collected Triatominae were crossed according to their phenotypes (e.g., $M$. longipennis x M. longipennis, $M$. picturatus $\mathrm{x} M$. picturatus etc.) with the purpose of establishing if each collected phenotype corresponded to a "pure" species (a group without any previous interfertility event) or if they were hybrids (specimen products of the crossing of individuals belonging to two unlike natural populations, principally of different species) (Mayr \& Ashlock 1991).

With the purpose of doing an analysis to determine fertility and the proportion of every phenotype, it was established that 20 individuals that reached the adult stage of the F1 offspring of each couple had to be studied. In order to obtain those 20 adults, 30 first instar nymphs were selected at the beginning because mortalities are usually from $20-60 \%$ in species of the Phyllosoma complex reared under similar laboratory conditions (Martínez-Ibarra et al. 2003, 2005, 2006). From those 20 adults, as many sibling crosses as possible were done (depending on the proportion between females and males, usually close to 1:1). Sibling males without a sibling female as a couple were crossed with a $M$. longipennis female (in the case of crosses of $M$. longipennis x $M$. pallidipennis and in crosses of $M$. longipennis x M. picturatus) and with a M. pallidipennis female (in the case of crosses of $M$. picturatus X $M$. pallidipennis) in order to determine their fertility.

Crosses of species from non-overlapping areas under laboratory conditions - Individuals used in crossing experiments were obtained from colonies established previously for at least six generations from Triatominae originating in non-overlapping areas. This was done to guarantee the purity of the colonies with respect to the exclusion of previous interfertility events between different species. The three colonies used in the experiments were composed of the three most distributed species of the Phyllosoma complex. The colony of M. picturatus was established with 23 individuals from Jala, Nayarit $\left(21^{\circ} 03^{\prime} \mathrm{N}, 104^{\circ} 26^{\prime} \mathrm{W}\right)$, the colony of M. longipennis was originated from 95 individuals from Teocuitatlán de Corona, Jalisco $\left(20^{\circ} 06^{\prime} \mathrm{N}, 103^{\circ} 21^{\prime} \mathrm{W}\right)$ and the colony of M. pallidipennis was initiated with 30 individuals col-

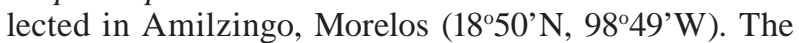
only overlapping species of Triatominae was Triatoma barberi Usinger, a species of smaller size. It was considered that their size prevented the risk of crossing with the other species of the complex. Collected individuals were identified following the Lent and Wygodzinsky (1979) keys and corresponded to the typical morphological characteristics of each species.

For carrying out the experimental interspecific crosses of this study, 20 couples were individually placed in 
plastic jars (5 cm diameter $\mathrm{x} 10 \mathrm{~cm}$ height) as follows: ten $M$. pallidipennis females and a $M$. longipennis male, ten M. pallidipennis males and a M. longipennis female, ten $M$. pallidipennis females and a $M$. picturatus male and ten M. pallidipennis males and a M. picturatus female. The developmental cycle of each parental lineage involved in the study was used as a control; most of these data have already been published (Martínez-Ibarra et al. 2003, Martínez-Ibarra \& Novelo-López 2004). Specimens were maintained within incubators at $27 \pm 1^{\circ} \mathrm{C}$ and $75 \pm 5 \%$ relative humidity and were fed weekly on New Zealand rabbits. Obtained offspring were also fed on rabbit blood and raised until they became adult insects. The first 20 nymphs that reached the 5th instar were sexed and separated into males and females. Every single phenotype was counted and maintained with weekly blood feedings.

Crosses of F1 individuals - To determine fertility of the offspring (F1) from the $M$. longipennis x M. pallidipennis and $M$. picturatus x $M$. pallidipennis groups, as in the case of individuals from the field collections, as many sibling crosses as possible were performed from those 20 adults (depending on the proportion between females and males, usually close to 1:1). Each female was checked daily for eggs. Collected eggs were observed for at least 25 days to determine viability. Once again, 30 1st instar nymphs (to get at least 20 adults, considering mortality percentages) of each of the crosses of each group (M. longipennis x M. pallidipennis and $M$. picturatus $\mathrm{x} M$. pallidipennis) were obtained and placed in plastic glasses (10 in each). In the same way, the nymphs were fed on rabbit blood and were reared to adults. Then, the phenotype of the offspring of each couple was described. After obtaining the F2 offspring, the segregation of phenotypes and their viability and fertility were determined.

$X^{2}$ tests were done to estimate differences between phenotypic frequencies in the studied offspring.

\section{RESULTS}

Collection of Triatominae in overlapping areas - M. longipennis and M. pallidipennis area - Most morphological characteristics of the specimens collected in natural and human ecotopes in Ahuacapán and Quitupan areas were of M. longipennis and M. pallidipennis, which led to classifying them as one or the other of these two species. However, it was assumed that those triatomines could be products of intercrosses because they were sympatric and in both species, the connexival plates had brown-yellow markings, different from the orange-red markings in typical specimens (Fig. 2). Around 100 specimens each of $M$. longipennis and M. pallidipennis were collected in the same habitats in Ahuacapán, whereas slightly more than $200 \mathrm{M}$. longipennis and $M$. pallidipennis (in a 1:3 relationship) were collected in Quitupan (Table I).

M. picturatus and M. pallidipennis area - A total of 194 specimens were collected. Approximately half were typical M. picturatus (Fig. 2), an eighth were typical M. pallidipennis (Fig. 2) and almost three-eighths were atypical specimens, apparently hybrids (Table I), with one obvious characteristic of one of each of the other two species in the area: a white-yellow corium of the hemelytra, like M. pallidipennis and an orange pronotum, like M. picturatus (Fig. 3), similar to those hybrids of M. picturatus and $M$. pallidipennis described by Mazzotti and Osorio (1942) and Mazzotti (1943).

\section{TABLE I}

Number of collected triatomines from overlapping areas of species of the Phyllosoma complex in Western Mexico

\begin{tabular}{|c|c|c|c|c|}
\hline & $\begin{array}{c}\text { Meccus } \\
\text { longipennis }\end{array}$ & $\begin{array}{c}\text { Meccus } \\
\text { picturatus }\end{array}$ & $\begin{array}{r}\text { Месси } \\
\text { pallidiper }\end{array}$ & Hybrids \\
\hline Species & $\mathrm{n}$ & $\mathrm{n}$ & $\mathrm{n}$ & $\mathrm{n}$ \\
\hline \multicolumn{5}{|l|}{ Locality } \\
\hline Ahuacapán & 99 & - & 104 & - \\
\hline Quitupan & 52 & - & 153 & - \\
\hline La Mesa & - & 102 & 26 & 66 \\
\hline La Mesita & 38 & 35 & - & - \\
\hline Francisco I. Madero & 78 & 23 & - & - \\
\hline Compostela & 89 & 27 & - & - \\
\hline Xalisco & 90 & 31 & - & - \\
\hline
\end{tabular}
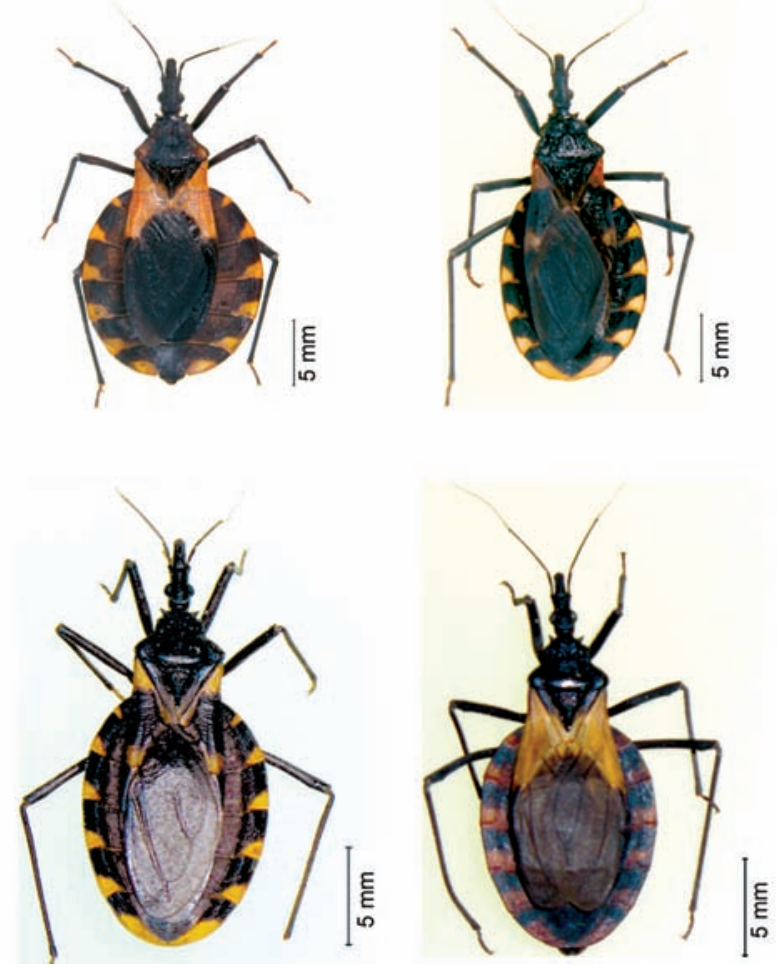

Fig. 2: different phenotypes of species of the Phyllosoma complex from Western Mexico (clock wise, beginning top left): atypical Meccus pallidipennis, atypical Meccus longipennis, typical M. pallidipennis, typical M. longipennis. 
M. longipennis and M. picturatus area - More than 400 triatomine specimens were collected in the study area. Almost 300 were $M$. longipennis and the rest were M. picturatus (Table I).

Morphological characteristics of specimens collected in natural and human ecotopes in La Mesita, Compostela, Francisco I. Madero and Xalisco areas were of typical $M$. picturatus and $M$. longipennis, which led to classifying them as one or the other of these two species (Figs 2, 3). However, it was assumed that specimens of those populations could be product of intercrosses because they were sympatric and it has also been previously established that those species could successfully interbreed (Martínez-Ibarra et al. 2008b).

Crosses of specimens from the field - M. longipennis and M. pallidipennis area - After carrying out crosses between specimens collected under field conditions and obtaining offspring, it was found that all analysed F1 individuals of crosses of M. pallidipennis x M. pallidipennis and M. longipennis x M. longipennis from Ahuacapán and Quitupan were viable and fertile because F1 individuals were crossed and they laid viable eggs, whose nymphs reached the 1st instar (data not shown). As assumed before, offspring from crosses of M. pallidipennis x M. pallidipennis showed that those individuals collected from the field were the product of interbreeding because more than one phenotype was obtained (Table II). As with their parents, F1 individuals of the two resulting phenotypes were almost typical, with the exception of their connexival plates, which had brown-yellow markings (Fig. 2).

M. picturatus and M. pallidipennis area - All triatomines collected in La Mesa were fertile (Table II) and had viable and fertile offspring (data not shown). In contrast to the previous case, all F1 offspring from crosses of $M$. picturatus x $M$. picturatus were M. picturatus and, in the case of the F1 generation from crosses of M. pallidipennis x M. pallidipennis, all were $M$. pallidipennis (Table II). Furthermore, in the crosses of hybrid $x$ hybrid, the offspring suggest that those individuals were the result of crossbreeding because three phenotypes were obtained. F1 individuals of M. picturatus as well as those of M. pallidipennis were typical. Finally, the third phenotype was apparently a hybrid (Fig. 3).

M. longipennis and M. picturatus area - It was found that all analysed F1 individuals of crosses between $M$. longipennis and M. longipennis and between M. picturatus and M. picturatus from La Mesita, Francisco I.
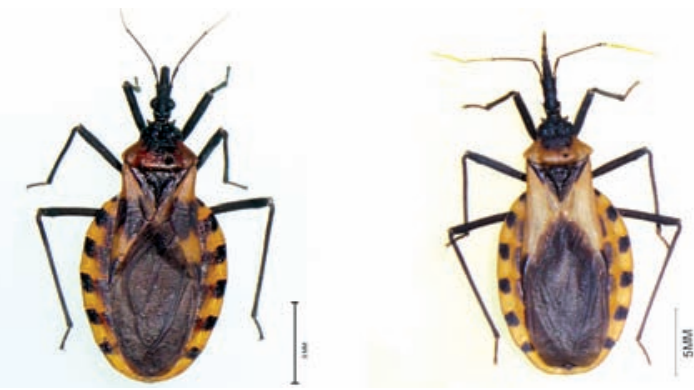

Fig. 3: phenotypes of specimens of Meccus picturatus: pure specimen (left), hybrid of M. picturatus x Meccus pallidipennis (right).

TABLE II

Crosses of sympatrically collected triatomines under field conditions

\begin{tabular}{|c|c|c|c|c|c|c|c|c|c|c|}
\hline \multirow[b]{3}{*}{ Locality } & \multirow{2}{*}{\multicolumn{2}{|c|}{ Crosses }} & \multicolumn{8}{|c|}{ F1 offspring (adults) } \\
\hline & & & \multicolumn{2}{|c|}{$M l$} & \multicolumn{2}{|c|}{ Mpi } & \multicolumn{2}{|c|}{ Мpa } & \multicolumn{2}{|c|}{$\mathrm{MH}$} \\
\hline & Phenotypes & $\mathrm{n}$ & q & $\hat{\sigma}$ & 우 & $\hat{0}$ & q & $\hat{0}$ & 우 & $\hat{\sigma}$ \\
\hline Ahuacapán & $M l \times M l$ & 45 & 458 & 442 & - & - & - & - & - & \\
\hline Ahuacapán & Мpa х Мpa & 47 & 338 & 330 & - & - & 141 & 131 & - & - \\
\hline Quitupan & $M l \times M l$ & 22 & 213 & 227 & - & - & - & - & - & - \\
\hline Quitupan & Мpa х $M p a$ & 74 & 554 & 569 & - & - & 174 & 183 & - & - \\
\hline La Mesa & M. pi x Mpi & 48 & - & - & 449 & 471 & - & - & - & - \\
\hline La Mesa & Mpa х $M p a$ & 14 & - & - & - & - & 144 & 136 & - & - \\
\hline La Mesa & $\mathrm{MH} \times \mathrm{MH}$ & 28 & - & - & 109 & 118 & 125 & 129 & 41 & 38 \\
\hline La Mesita & $M l \times M l$ & 16 & 148 & 141 & 14 & 17 & - & - & - & - \\
\hline La Mesita & $M p i \times M p i$ & 15 & 37 & 35 & 118 & 110 & - & - & - & - \\
\hline Francisco I. Madero & $M l \times M l$ & 36 & 333 & 347 & 18 & 22 & - & - & - & - \\
\hline Francisco I. Madero & Mpi x Mpi & 10 & 24 & 25 & 71 & 80 & - & - & - & - \\
\hline Compostela & $M l \times M l$ & 41 & 384 & 377 & 28 & 31 & - & - & - & - \\
\hline Compostela & Mpi x Mpi & 11 & 26 & 31 & 79 & 84 & - & - & - & - \\
\hline Xalisco & $M l \times M l$ & 40 & 375 & 371 & 25 & 29 & - & - & - & - \\
\hline Xalisco & $M p i \times M p i$ & 12 & 26 & 33 & 93 & 88 & - & - & - & - \\
\hline
\end{tabular}

MH: morphological hybrid; Ml: Meccus longipennis; Mpa: M. pallidipennis; Mpi: Meccus picturatus. 
Madero, Compostela and Xalisco were viable and fertile because F1 individuals that were crossed laid viable eggs, whose nymphs reached the 1st instar (data not shown). As assumed before, the offspring showed that those individuals collected from the field were the product of interbreeding because more than one phenotype was obtained. As with their parents, F1 individuals of the two resulting phenotypes were typical specimens (Figs 2, 3).

Crosses of species from non-overlapping areas under laboratory conditions - M. pallidipennis x M. longipennis - The $400 \mathrm{~F} 1$ triatomines obtained from the 20 crosses were phenotypically M. pallidipennis (with white corium of hemelytra) and were fertile because 200 crosses of F1 individuals produced viable F2 progeny, independently of maternal species (Table III). Distribution of phenotypes among the F2 offspring was as follows: 2,873 M. pallidipennis and 987 M. longipennis (Table III). Segregation of the most prominent different morphological characteristics (corium colour) of these F2 progeny seemed to follow a Mendelian pattern because the proportion observed (3:1) gave a non-significant difference $(p>0.05)$ when the expected and observed phenotypes were compared.

M. pallidipennis x M. picturatus - All of the crosses were fertile and $400 \mathrm{~F} 1$ Triatominae were obtained and analysed. All F1 offspring were apparent hybrids (Fig. 3 , Table IV). Those triatomines were morphologically similar to the reported apparent hybrids collected under field conditions in La Mesa, Jalisco. Of the 194 crosses performed from the F1 individuals, all of the analysed offspring (F2) were viable and reached the adult stage. Segregation of the two outstanding morphological characteristics (corium and pronotum colour) appeared to not follow either a Mendelian pattern or a co-dominance relationship. More studies are needed in order to determine the inheritance patterns. The distribution of phenotypes among the F2 offspring was close to 1:3:1 (M. picturatus, apparent hybrids and M. pallidipennis) (Table IV), giving a non-significant difference $(p>0.05)$ when the expected and observed phenotypes were compared.

\section{DISCUSSION}

In Mexico, few studies (Breniere et al. 2007, Martínez-Ibarra et al. 2008a) have reported collection of natural atypical (individuals with morphological characteristics of two species considered hybrids) specimens of the Phyllosoma complex species. It is hypothesized that the lack of a previous report of those kinds of naturally-occurring specimens could be due to different reasons. First of all, it could be that hybrids would have been unnoticed by collectors in some areas of sympatry because the collectors may have lacked the awareness of potentially collecting hybrids because in many cases, specimens of those kinds of offspring are morphologically indistinguishable from one or both parental lines, as happened when different species of the Phyllosoma complex were crossed under laboratory conditions

TABLE III

Experimental crosses of “pure” individuals of Meccus longipennis x Meccus pallidipennis

\begin{tabular}{|c|c|c|c|c|c|c|c|c|c|}
\hline \multirow{3}{*}{$\begin{array}{l}\text { Crossing species } \\
\text { (20 crosses) }\end{array}$} & \multicolumn{4}{|c|}{$\begin{array}{l}\text { F1 outspring } \\
\text { (adults) }\end{array}$} & \multirow{3}{*}{$\begin{array}{l}\text { Crossing F1 phenotypes } \\
\text { (193 crosses) }\end{array}$} & \multicolumn{4}{|c|}{$\begin{array}{l}\text { F2 offspring } \\
\text { (adults) }\end{array}$} \\
\hline & \multicolumn{2}{|c|}{ M. pallidipennis } & \multicolumn{2}{|c|}{ M. longipennis } & & \multicolumn{2}{|c|}{ M. pallidipennis } & \multicolumn{2}{|c|}{ M. longipennis } \\
\hline & q & $\hat{0}$ & q & $\hat{\delta}$ & & q & 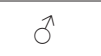 & o & $\delta$ \\
\hline M. longipennis & & & & & M. pallidipennis & & & & \\
\hline $\begin{array}{c}\mathrm{x} \\
\text { M. pallidipennis }\end{array}$ & 193 & 207 & - & - & $\begin{array}{c}\mathrm{x} \\
\text { M. pallidipennis }\end{array}$ & 1,451 & 1,422 & 496 & 491 \\
\hline
\end{tabular}

TABLE IV

Experimental crosses of “pure” individuals of Meccus pallidipennis x Meccus picturatus

\begin{tabular}{|c|c|c|c|c|c|c|c|c|c|c|c|}
\hline \multirow{3}{*}{$\begin{array}{l}\text { Crossing species } \\
\text { ( } 20 \text { crosses) }\end{array}$} & \multirow{2}{*}{\multicolumn{3}{|c|}{$\begin{array}{c}\begin{array}{c}\text { F1 offspring } \\
\text { (adults) }\end{array} \\
\text { Hybrid } \\
\end{array}$}} & \multirow[b]{3}{*}{ M. palldipennis } & \multirow{3}{*}{$\begin{array}{l}\text { Crossing F1 phenotypes } \\
\text { (194 crosses) }\end{array}$} & \multicolumn{6}{|c|}{$\begin{array}{l}\text { F2 offspring } \\
\text { (adults) }\end{array}$} \\
\hline & & & & & & \multicolumn{2}{|c|}{ M. picturatus } & \multicolumn{2}{|c|}{ Hybrid } & \multicolumn{2}{|c|}{ M. pallidipennis } \\
\hline & M. picturatus & q & $\delta$ & & & q & $\delta$ & q & $\hat{0}$ & 우 & $\hat{0}$ \\
\hline M. palldipennis & & & & & Morphological hybrid & & & & & & \\
\hline M. picturatus & - & 194 & 206 & - & $\begin{array}{c}\text { X } \\
\text { Morphological hybrid }\end{array}$ & 407 & 411 & 1,154 & 1,143 & 384 & 381 \\
\hline
\end{tabular}


(Martínez-Ibarra et al. 2008b). Another reason could be that the overlapping area was very limited and/or inaccessible, such as in the La Mesa and La Mesita areas from which some hybrids were collected and reported on in this research.

In this study, both apparently typical and atypical individuals were carefully inspected until offspring reached the adult stage. This kind of study is very important to understand the taxonomy of Triatominae, especially those involving some species of the Phyllosoma complex. Special attention should be placed on triatomines collected from the same locality in the overlapping areas of two or more species of the Phyllosoma complex because of the similarities between the different species of this complex. This could lead to establishing no reliable phylogenetic relationships, as could have happened in two studies (Flores et al. 2001, Marcilla et al. 2001) in which individuals of $M$. longipennis and $M$. picturatus, species that can intercross and have hybrid offspring, were collected from the same or close towns in Western Mexico.

All descendants studied from the crosses of hybrid and "pure" individuals from the laboratory were fully fertile and, in the cases tested, had viable offspring, which could indicate that no reproductive isolation barriers have been developed.

Mayr (2000) defined biological species "as groups of interbreeding natural populations that are reproductively isolated from other such groups". Alternatively, he said "that a biological species is a reproductive cohesive assemblage of populations". Mayr and Ashlock (1991) established that when two populations interbreed completely in a (usually rather narrow) zone of contact of hybridization, they have to be treated as subspecies. According to Mayr and Diamond (2001), the subspecies "are local populations that are recognizably different from each other but that are nevertheless considered to belong to the same species, because they are observed to interbreed in nature or because it is inferred that they are likely to interbreed". Taking into account those two concepts, we consider that the level of subspecies is more appropriate for the individuals of the Phyllosoma complex, as had been suggested before (Mazzotti \& Osorio 1942, Usinger et al. 1966, Martínez et al. 2005, 2006, 2010, Bargues et al. 2008). This assumption is supported by some molecular studies on the species of the Phyllosoma complex, in which it was established that the genetic differences between those taxa (species) are so small (sometimes even none at all) that there is no support to maintain them as separate species (Bargues et al. 2008). Furthermore, their divergence is estimated at only 0.74-2.28 Mya by the rDNA molecular clock, which also seems consistent with the subspecific rank (Bargues et al. 2000). Moreover, ITS-2 and CytB markers and the use of antennal phenotype studies have always reached the same conclusion (Marcilla et al. 2001, Bargues et al. 2002, Martínez et al. 2006, 2010). By analyzing many interfertile experiments (Mazzotti \& Osorio 1942, Martínez-Ibarra et al. 2008b), it can be concluded that in triatomines, morphological differentiation appears faster than the appearance of reproductive or genetic barriers (Dujardin et al. 1999, Bargues et al. 2008). As Mayr and Ashlock (1991) established, only subspecies that are isolated are incipient species, whereas subspecies that are part of a continuum are not. Furthermore, comparison of the small genetic divergences between these taxa and the facts that their distributions are exclusively restricted to Mexico and their geographical distribution areas have broad zones of overlap suggest that the genetic exchange might be impeding or delaying definitive divergence processes to reach a species level of $M$. longipennis, M. picturatus and M. pallidipennis, as proposed by Bargues et al. (2008).

Additionally, these results support recent evolutionary relationships and probably reflect the divergence from a common ancestor (Flores et al. 2001, Martínez et al. 2005) because apparently, as soon as a population of one of these species colonizes the habitat of another, both can mate and have fertile offspring.

In conclusion, our results support the hypothesis that M. longipennis, M. picturatus and M. pallidipennis are subspecies of M. phyllosomus. The modification of the taxonomic status of these species to subspecies is proposed and the names $M$. phyllosomus longipennis, $M$. phyllosomus picturatus and M. phyllosomus pallidipennis are suggested.

\section{ACKNOWLEDGEMENTS}

To Fernando Martínez, for his unvaluable help.

\section{REFERENCES}

Bargues MD, Klisiowicz DR, González-Candelas F, Ramsey JM, Monroy C, Ponce C, Salazar-Schettino PM, Panzera F, AbadFranch F, Souza OE, Schofield CE, Dujardin JP, Guhl F, Mas-Coma S 2008. Phylogeography and genetic variation of Triatoma dimidiata, the main Chagas disease vector in Central America and its position within the genus Triatoma. PLos Negl Trop Dis 2: e233.

Bargues MD, Marcilla A, Dujardin JP, Mas-Coma S 2002. Triatomine vectors of Chagas disease: a molecular perspective based on nuclear ribosomal DNA markers. Trans Roy Soc Trop Med Hyg 96: 159-164.

Bargues MD, Marcilla A, Ramsey JM, Dujardin JP, Schofield CJ, Mas-Coma S 2000. Nuclear rDNA-based molecular clock of the evolution of Triatominae (Hemiptera: Reduviidae), vectors of Chagas disease. Mem Inst Oswaldo Cruz 95: 567-573.

Bosseno MF, Barnabé C, Ramírez-Sierra MJ, Kengne P, Guerrero S, Lozano-Kasten F, Magallón-Gastélum E, Breniere SF 2009. Wild ecotopes and food habits of Triatoma longipennis infected by Trypanosoma cruzi lineages I y II in Mexico. Am J Trop Med Hyg 80: 988-991.

Breniere SF, Bosseno MF, Magallón-Gastélum E, Castillo-Ruvalcaba EG, Soto-Gutiérrez M, Montaño-Luna EC, Tejeda-Basulto J, Mathieu-Daudé F, Walter A, Lozano-Kasten F 2007. Peridomestic colonization of Triatoma longipennis (Hemiptera: Reduviidae) and Triatoma barberi (Hemiptera: Reduviidae) in a rural community with active transmission of Trypanosoma cruzi in Jalisco state, Mexico. Acta Trop 101: 249-257.

Cruz-Reyes A, Pickering-López JM 2006. Chagas disease in Mexico: an analysis of geographical distribution during the past 76 years - A review. Mem Inst Oswaldo Cruz 101: 334-354.

Dujardin JP, Panzera F, Schofield CJ 1999. Triatominae as a model of morphological plasticity under ecological pressure. Mem Inst Oswaldo Cruz 94: (Suppl. I) 223-228. 
Espinoza-Gómez F, Maldonado-Rodríguez A, Coll-Cárdenas R, Hernández-Suárez CM, Fernández-Salas I 2002. Presence of Triatominae (Hemiptera: Reduviidae) and risk of transmission of Chagas disease in Colima, Mexico. Mem Inst Oswaldo Cruz 97: 25-30.

Flores A, Magallón-Gastélum E, Bosseno MF, Ordóñez R, LozanoKasten F, Espinoza B, Ramsey J, Breniere SF 2001. Isoenzyme variability of five principal triatomine vector species of Chagas disease in Mexico. Infect Genet Evol 4: 1-8.

Lent H, Wygodzinsky P 1979. Revision of the Triatominae (Hemiptera: Reduviidae) and their significance as vectors of Chagas disease. Bull Am Mus Nat Hist 163: 123-520.

Marcilla A, Bargues MD, Ramsey JM, Magallón-Gastélum E, Salazar-Schettino PM, Abad-Franch F, Dujardin JP, Schofield CJ, Mas-Coma S 2001. The ITS-2 of the nuclear rDNA as a molecular marker for populations, species and phylogenetic relationships in Triatominae (Hemiptera: Reduviidae), vector of Chagas disease. Mol Phylogenet Evol 18: 136-142.

Martínez F, Alejandre-Aguilar R, Hortelano-Moncada Y, Espinoza B 2005. Molecular taxonomic study of Chagas disease vectors from the Phyllosoma, Lecticularia and Rubrofasciata complexes. Am J Trop Med Hyg 73: 321-325.

Martínez F, Martínez-Ibarra JA, Catalá S, Villalobos G, de la Torre P, Laclette J, Alejandre-Aguilar R, Espinoza B 2010. Natural crossbreeding between sympatric species of the Phyllosoma complex (Insecta: Hemiptera: Reduviidae) indicate the existence of only one species with morphologic and genetic variations. Am J Trop Med Hyg, in press.

Martínez HF, Villalobos CG, Ceballos AM, De la Torre P, Laclette JP, Alejandre-Aguilar R, Espinoza B 2006. Phylogenetic analysis of Triatominae (Hemiptera: Reduviidae) species of epidemiological importance in the transmission of Chagas disease: nuclear DNA vs. mitochondrial DNA as molecular markers. Mol Phylogenet Evol 41: 279-287.

Martínez-Ibarra JA, Alejandre-Aguilar R, Torres-Morales A, Trujillo-García JC, Nogueda-Torres B, Trujillo-Contreras F 2006. Biology of three species of the Meccus phyllosomus complex (Hemiptera: Reduviidae: Triatominae) fed on blood of hens and rabbits. Mem Inst Oswaldo Cruz 101: 787-794.

Martínez-Ibarra JA, Bárcenas-Ortega NM, Nogueda-Torres B, Alejandre-Aguilar R, Rodríguez ML, Magallón-Gastélum E, López-Martínez V, Romero-Nápoles J 2001. Role of two Triatoma (Hemiptera: Reduviidae: Triatominae) species in the transmission of Trypanosoma cruzi (Kinetoplastida: Trypanosomatidae) to man in the west coast of Mexico. Mem Inst Oswaldo Cruz 96: 141-144.

Martínez-Ibarra JA, Grant-Guillén Y, Morales-Corona ZY, HaroRodriguez S, Ventura-Rodríguez LV, Nogueda-Torres B, BustosSaldaña R 2008a. Importance of species of Triatominae (Heteroptera: Reduviidae) in the risk of transmission of Trypanosoma cruzi in Western Mexico. J Med Entomol 45: 476-482.

Martínez-Ibarra JA, Nogueda-Torres B, Paredes-González E, Alejandre-Aguilar R, Solorio-Cibrián M, Barreto SP, Gómez-Estrada
HI, Trujillo-García JC 2005. Development of Triatoma rubida sonoriana, Triatoma barberi and Meccus mazzottii (Heteroptera: Reduviidae) under laboratory conditions. J Am Mosq Cont Assoc 21: 310-315.

Martínez-Ibarra JA, Novelo-López M 2004. Biological parameters of Meccus pallidipennis Stal (Hemiptera: Reduviidae) under laboratory conditions. Folia Entomol Mex 43: 313-319.

Martínez-Ibarra JA, Novelo-López M, Hernández-Robles MR, Grant Guillén Y 2003. Influence of the blood meal source on the biology of Meccus picturatus Usinger 1939 (Hemiptera: Reduviidae: Triatominae) under laboratory conditions. Mem Inst Oswaldo Cruz 98: 227-232.

Martínez-Ibarra JA, Ventura-Rodríguez LV, Meillon K, BarajasMartínez HM, Alejandre-Aguilar R, Lupercio-Coronel P, RochaChávez G, Nogueda-Torres B 2008b. Biological and genetic aspects of crosses between species of the Phyllosoma complex (Hemiptera: Reduviidae: Triatominae). Mem Inst Oswaldo Cruz 103: 236-243.

Martínez-Ibarra JA, Villagrán-Hernández MA, De Diego JA 2009. Infected reservoir host and vectors in an area of active transmission of Chagas disease in Western Mexico. Trop Med Int Health 14: 177.

Mayr E 2000. The biological species concept. In QD Wheeler, R Meier (eds.), Species concepts and phylogenetic theory. A debate, Columbia University Press, New York, p. 17-29.

Mayr E, Ashlock PD 1991. Principles of systematic zoology, McGrawHill, New York, 475 pp.

Mayr E, Diamond J 2001. The birds of Northern Melanesia, Oxford University Press, Oxford, 492 pp.

Mazzotti L 1943. Triatoma phyllosoma usingeri, a new subspecies of Triatoma from Mexico. Pan-Pacific Entomol 19: 80-85.

Mazzotti L, Osorio MT 1942. Cruzamientos experimentales entre varias especies de triatomas. Rev Mex Med 22: 215-222.

Pinchin R, Fanara DM, Castleton CW, Oliveira-Filho AM 1981. Comparison of techniques for detection of domestic infestations with Triatoma infestans in Brazil. Trans $R$ Soc Trop Med Hyg 75: 691-694.

Sandoval-Ruiz CA, Zumaquero JL Rojas-Soto OR 2008. Predicting geographic and ecological distributions of triatomine species in the Southern Mexican state of Puebla sing ecological niche modeling. J Med Entomol 45: 540-546.

SEGOB - Secretaría de Gobernación 2005. [cited 23 June 2009]. Enciclopedia de los municipios de México. Available from http:// www.e-local.gob.mx.wb/ELOCAL/ELOC_Enciclopedia.

SSJ - Secretaría de Salud en Jalisco 2005. Programa de prevención y control de Chagas, Dirección General de Salud Pública, Departamento de vectores y zoonosis, SSJ, Guadalajara, 41 pp.

Usinger RL, Wygodzinsky P, Ryckman R 1966. The biosystematics of Triatominae. Annu Rev Entomol 11: 309-330. 